\title{
Synthesis of molecularly imprinted polypyrrole/titanium dioxide nanocomposites and its selective photocatalytic degradation of rhodamine $B$ under visible light irradiation
}

\author{
M. Q. He , L. L. Bao, K. Y. Sun, D. X. Zhao, W. B. Li, J. X. Xia, H. M. Li \\ School of Chemistry and Chemical Engineering, Jiangsu University, Zhenjiang, 212013 Jiangsu, China
}

Received 15 April 2014; accepted in revised form 13 June 2014

\begin{abstract}
Highly selective molecularly imprinted nanocomposites $\mathrm{MIP}_{\mathrm{RhB}}-\mathrm{PPy} / \mathrm{TiO}_{2}$ were successfully prepared by surface molecular imprinting technique with rhodamine $\mathrm{B}(\mathrm{RhB})$ as template molecule. The prepared $\mathrm{MIP} \mathrm{RhB}_{\mathrm{Rh}}-\mathrm{PPy} / \mathrm{TiO}_{2}$ coated with a thin imprinted layer could respond to visible light. The static and dynamic binding experiments revealed that $\mathrm{MIP}_{\mathrm{RhB}}-\mathrm{PPy} / \mathrm{TiO}_{2}$ possessed strong affinity, high adsorption capacity and fast adsorption rate for RhB. The selectivity experiments indicated that $\mathrm{MIP}_{\mathrm{RhB}}-\mathrm{PPy} / \mathrm{TiO}_{2}$ had excellent recognition selectivity for $\mathrm{RhB}$. Selective photocatalytic degradation experiments indicated that the apparent rate constant $(k)$ for the photodegradation of $\mathrm{RhB}$ over $\mathrm{MIP} \mathrm{RhB}_{-}-\mathrm{PPy} / \mathrm{TiO} \mathrm{O}_{2}$ is $0.0158 \mathrm{~min}^{-1}$, being 3.6 times of that over non-imprinted nanocomposites NIP-PPy/TiO $\left(0.0044 \mathrm{~min}^{-1}\right)$. Compared with the NIP-PPy $/ \mathrm{TiO}_{2}, \mathrm{MIP}_{\mathrm{RhB}}-\mathrm{PPy} / \mathrm{TiO}_{2}$ showed higher photocatalytic selectivity toward $\mathrm{RhB}$ under visible light, which was attributed the introduction of the imprinted cavities on the surface of $\mathrm{MIP}_{\mathrm{RhB}}-\mathrm{PPy} / \mathrm{TiO}_{2}$. Moreover, $\mathrm{MIP}_{\mathrm{RhB}}-\mathrm{PPy} / \mathrm{TiO}{ }_{2}$ exhibited high reusability and stability. The results indicate that molecularly imprinted nanocomposites $\mathrm{MIP} \mathrm{RhB}_{\mathrm{R}}-\mathrm{PPy} / \mathrm{TiO}{ }_{2}$ have a promising perspective in industrial wastewater treatment.
\end{abstract}

Keywords: nanocomposites, photodegradation, selectivity, molecular imprinting, rhodamine B

\section{Introduction}

Titanium dioxide $\left(\mathrm{TiO}_{2}\right)$ photocatalyst as a semiconductor material has been well studied for photocatalytic degradation of pollutants due to its inexpensive, non-toxic, good stability, excellent photoelectric properties and reusable performances [1-3]. However, it has a wide band gap (3.0-3.2 eV), and usually cannot be effectively activated by the solar light for degradation of pollution [4]. Much work have been tried to improve the photocatalytic efficiency of $\mathrm{TiO}_{2}$ under visible light irradiation by transforming its optical response from the UV to the visible range, such as by metal doping $[5,6]$, nonmetal doping [7, 8], surface dye sensitization [9] and forming composites with other semiconductors [10, 11]. Recently, conductive polymers have emerged as stable photosensitizers to modify $\mathrm{TiO}_{2}$ nanoparticles owning to their remarkable physical attributes and electrical properties [12]. Among various conductive polymers, polypyrrole (PPy) is one of the most promising conductive polymers due to its high absorption coefficients in the visible part of the spectrum, superior conductivity, electrochemical reversibility, high thermal stability and non-toxicity nature [13-17]. Some publications have been reported that $\mathrm{PPy} / \mathrm{TiO}_{2}$ nanocomposites showed higher adsorption capacity and better photocatalytic activity under visible light irradiation than that of neat $\mathrm{TiO}_{2}$ nanoparticles [18-21].

Although the photocatalytic degradation activity of the modified photocatalyst is improved, the selective degradation of targeted pollutants is very poor

\footnotetext{
${ }^{*}$ Corresponding author, e-mail: hemq@ujs.edu.cn

(C) BME-PT
} 
as the reactivity of the hydroxyl radical is difficult to control. When applied to environmental treatment, photocatalysis may not be efficient if it aims to remove all pollutants by itself [22]. Therefore, it is important to find a way to selectively remove the targeted pollutants. In recent years several approaches have been proposed to enhance the selectivity of photocatalyst such as $\mathrm{pH}$ adjustment to control of surface electric charge [23], specific molecules modified surface of $\mathrm{TiO}_{2}$ [24], double-region-structured photocatalysts [25], and using the molecular imprinting technique (MIT) for selective removal the organic pollutant [26]. Among these methods, MIT combined with photocatalytic technology exhibit higher efficient to enhance the selectivity of photocatalyst for degradation of targeted organic pollutants.

MIT is a promising way for synthesizing threedimensional cross-linked polymers to achieve specific molecular recognition properties [27]. The molecularly imprinted polymers (MIPs), for its chemical/mechanical stability, high selectivity, low cost, and preparation simplicity, has been applied in many fields such as specific separation [28], solidphase extraction [29], reactive catalysis [30], and sensors [31]. Compared with conventional MIPs, the surface imprinting polymers (SMIPs) which control the imprinted cavities to be situated at the surface or in the proximity of materials process more accessible sites, faster mass transfer, and higher adsorption capacity for template molecules. Based on the surface molecular imprinting technique (SMIT), Shen et al. [26] prepared a series of MIPcoated $\mathrm{TiO}_{2}$ photocatalysts, the photodegradation experiments confirmed that the photocatalysts have good selectivity toward the two nitrophenols in both single and binary systems. Luo et al. [32] prepared inorganic-framework molecularly imprinted $\mathrm{TiO}_{2} /$ $\mathrm{WO}_{3}$, The photocatalytic activity of molecularly imprinted $\mathrm{TiO}_{2} / \mathrm{WO}_{3}$ toward the target molecules is more than two times that of non-imprinted $\mathrm{TiO}_{2} /$ $\mathrm{WO}_{3}$, a result of selective adsorption of target molecules on molecularly imprinted $\mathrm{TiO}_{2} / \mathrm{WO}_{3}$. Huo et al. [33] prepared the imprinted photocatalyst of polyo-phenylenediamine (POPD) modified the $\mathrm{TiO}_{2} /$ flyash cenospheres, compared with the non imprinted photocatalysts, it could effectively select degradation of the targeted POPD in environment. The above approach, however, has some drawbacks such as a layer of organic polymer may hinder light absorp- tion and could be degraded during photocatalysis. Therefore, it is crucial to obtain steady imprinted polymer and control the thickness of the imprinted layer.

In our study, a highly selective molecularly imprinted nanocomposite $\mathrm{MIP}_{\mathrm{RhB}}-\mathrm{PPy} / \mathrm{TiO}_{2}$ was successfully prepared by adopting the SMIT with $\mathrm{TiO}_{2}$ as the support material, rhodamine $\mathrm{B}(\mathrm{RhB})$ as template molecule, respectively. The as-prepared $\mathrm{MIP}_{\mathrm{RhB}^{-}}$ $\mathrm{PPy} / \mathrm{TiO}_{2}$ coated with a thin layer of MIP not only exhibits high adsorption capacity and selectivity for $\mathrm{RhB}$, but also can improve molecular recognitive photocatalytic activity under visible light irradiation. The adsorption characteristics of $\mathrm{MIP}_{\mathrm{RhB}}-\mathrm{PPy} /$ $\mathrm{TiO}_{2}$ were explored using static and dynamic binding experiments, the adsorption selectivity of $\mathrm{MIP}_{\mathrm{RhB}^{-}}$ $\mathrm{PPy} / \mathrm{TiO}_{2}$ was also investigated. In addition, the selective photocatalytic degradation activity of MIP $\mathrm{RhB}-\mathrm{PPy} / \mathrm{TiO}_{2}$ towards $\mathrm{RhB}$ was discussed in detail.

\section{Experimental \\ 2.1. Reagents}

All chemical reagents were used as received without further purification. $\mathrm{TiO}_{2}$ nanoparticles (P25) were obtained from Degussa (Germany). Iron (III) chloride hexahydrate $\left(\mathrm{FeCl}_{3} \cdot 6 \mathrm{H} 2 \mathrm{O}\right)$ was obtained from Shanghai Meryer Chemical Reagent Co. (China), Ltd. Polypyrrole (PPy) was purchased from Lark Technology Co., Ltd. (UK), Rhodamine B $(\mathrm{RhB})$ was obtained from Shanghai Sinopharm Chemical Co., Ltd. (China) Rhodamine 6G (Rh6G) was purchased from Shanghai Maikun Chemical Co., Ltd. (China), Methylene Blue (MB) was provided by Beijing Chemical Reagent Co. (China) Hydrochloric acid and ammonia aqueous were purchased from Shanghai Zhongshi Chemistry Co., Ltd. (China).

\subsection{Characterization}

X-ray diffraction (XRD) measurements were performed on a Philips X' pert MPD Pro X-ray diffractometer using $\mathrm{Cu} \mathrm{K} \alpha$ radiation $(\lambda=1.5406 \AA)$. Transmission electron microscope was recorded with a JEOL-IEM-200CX microscope. A UV-2450 Ultraviolet-visible Spectrophotometer (Shimadzu, Japan) was used to obtain the reflectance spectra of the photocatalysts over a range of $200-800 \mathrm{~nm}$, using $\mathrm{BaSO}_{4}$ as a reflectance reference. The specific surface area of $\mathrm{MIP}_{\mathrm{RhB}}-\mathrm{PPy} / \mathrm{TiO}_{2}$ and NIP-PPy $/ \mathrm{TiO}_{2}$ 
were determined by Brunauer-Emmett-Teller (BET) method.

The photocurrent experiments were measured in $\mathrm{Na}_{2} \mathrm{SO}_{4}$ aqueous $\left(0.2 \mathrm{~mol} \cdot \mathrm{L}^{-1}\right)$ solution under the irradiation of $500 \mathrm{~W}$ Xenon lamp. A standard threeelectrode configuration was used in the experiments. The indium-tin oxide (ITO) glass $(1 \mathrm{~cm} \times 1 \mathrm{~cm})$ coated with as-prepared samples $(0.1 \mathrm{mg})$ was used as working electrodes, a Pt wire was used as the counter electrode, and a saturated $\mathrm{Ag} / \mathrm{AgCl}$ electrode was used as the reference electrode. A CHI660B electrochemical workstation (Chen Hua Instruments, China) was photocurrent test systems.

\subsection{Preparation of $\mathrm{MIP} \mathrm{RhB}_{\mathrm{B}}-\mathrm{PPy} / \mathrm{TiO}_{2}$ nanocomposites}

The $\mathrm{TiO}_{2}$ nanoparticles $(2.0 \mathrm{~g})$ were dispersed in hydrochloric acid $(100 \mathrm{~mL}, \mathrm{pH}=2)$ in four-necked round bottomed flask and sonicated for $30 \mathrm{~min}$. $\mathrm{RhB}$ $(0.03 \mathrm{~g}, 0.06 \mathrm{mmol})$ and pyrrole $(17.3 \mu \mathrm{L}, 0.25 \mu \mathrm{mol})$ were dissolved in mixed solvent of methanol and water $(1: 1, \mathrm{v} / \mathrm{v})$, and the mixture was stirred in dark for $30 \mathrm{~min}$. Then the solution was injected into the previous four-necked round bottomed flask at $0^{\circ} \mathrm{C}$ with constant stirring. After that, hydrochloric acid $(2 \mathrm{~mL}, \mathrm{pH}=2)$ containing $\mathrm{FeCl}_{3} \cdot 6 \mathrm{H}_{2} \mathrm{O}(0.45 \mathrm{~g}$, $0.0017 \mathrm{mmol}$ ) was added dropwise to the above cooled mixture. The mixture was permitted to react at $0^{\circ} \mathrm{C}$ for $4 \mathrm{~h}$ with continuous stirring. The product particles were washed repeatedly with ammonia aqueous solution $(\mathrm{pH}=8)$ to remove the targeted $\mathrm{RhB}$ and then washed with distilled water to remove remaining ammonia. Finally, molecularly imprinted polypyrrole titanium dioxide nanocomposites $\left(\mathrm{MIP}_{\mathrm{RhB}}-\mathrm{PPy} / \mathrm{TiO}_{2}\right)$ were obtained by centrifugation and drying.

As a contrast, the non-imprinted nanocomposites (NIP-PPy/ $\mathrm{TiO}_{2}$ ) were prepared in the absence of the template and treated by using the same method.

\subsection{Binding experiments in dark}

\subsubsection{Batch mode binding experiments}

The adsorption kinetics behaviour of $\mathrm{MIP}_{\mathrm{RhB}}-\mathrm{PPy} /$ $\mathrm{TiO}_{2}$ for $\mathrm{RhB}$ was firstly measured at room temperature. $\mathrm{MIP}_{\mathrm{RhB}}-\mathrm{PPy} / \mathrm{TiO}_{2}(10 \mathrm{mg})$ was added into $\mathrm{RhB}$ aqueous solutions $(80 \mu \mathrm{mol} / \mathrm{L})$ and then the mixture was agitated in a shaken bed. After an interval of time, the mixture was centrifuged, and the supernatant solution was collected, and diluted with water to a certain times. Finally, the concentration of $\mathrm{RhB}$ was determined by UV-vis spectrophotometer at the maximum absorption wavelength of $\mathrm{RhB}$. The adsorption amount $(Q)$ was calculated by Equation (1):

$Q=\frac{\left(C_{0}-C_{\mathrm{t}}\right) V}{W}$

where $Q[\mu \mathrm{mol} / \mathrm{g}]$ is the adsorption amount of $\mathrm{MIP}_{\mathrm{RhB}}-\mathrm{PPy} / \mathrm{TiO}_{2}$ for $\mathrm{RhB}, W[\mathrm{~g}]$ is the weight of the $\mathrm{MIP}_{\mathrm{RhB}}-\mathrm{PPy} / \mathrm{TiO}_{2}$ nanocomposites, $V[\mathrm{~L}]$ is the volume of solution, $C_{0}[\mu \mathrm{mol} / \mathrm{L}]$ is the initial concentration of $\mathrm{RhB}$ and $C_{\mathrm{t}}[\mu \mathrm{mol} / \mathrm{L}]$ is the concentration of RhB at the time of $t$.

For the determination of the static binding behavior of $\mathrm{MIP}_{\mathrm{RhB}}-\mathrm{PPy} / \mathrm{TiO}_{2}$ for $\mathrm{RhB}$, numbers of $\mathrm{RhB}$ aqueous solutions with different concentrations were taken into centrifuge tubes. Then $10 \mathrm{mg}$ of $\mathrm{MIP}_{\mathrm{RhB}^{-}}$ $\mathrm{PPy} / \mathrm{TiO}_{2}$ or NIP-PPy $/ \mathrm{TiO}_{2}$ was added into the above solutions, respectively. These mixtures were agitated on a shaken bed at room temperature and centrifuged after reaching binding equilibrium. The supernatant solution was collected and diluted with water to a certain times. Finally, the equilibrium concentrations of $\mathrm{RhB}$ in the supernatants were determined by UV-vis spectrophotometer. The adsorption amount $\left(Q_{\mathrm{e}}, \mu \mathrm{mol} / \mathrm{g}\right)$ was calculated by Equation (2):

$Q_{\mathrm{e}}=\frac{\left(C_{0}-C_{\mathrm{e}}\right) V}{W}$

where $W[\mathrm{~g}]$ is the weight of $\mathrm{MIP} \mathrm{RhB}-\mathrm{PPy} / \mathrm{TiO}_{2}$ or NIP-PPy/TiO,$V[L]$ is the volume of the solution, $C_{0}[\mu \mathrm{mol} / \mathrm{L}]$ and $C_{\mathrm{e}}[\mu \mathrm{mol} / \mathrm{L}]$ are the initial concentration and the equilibrium concentration of $\mathrm{RhB}$, respectively.

The binding parameters of $\mathrm{MIP} \mathrm{RhB}_{-}-\mathrm{PPy} / \mathrm{TiO}_{2}$ are mainly estimated by Scatchard analysis with the data of static adsorption experiment. Scatchard equation is described by Equation (3):

$$
\frac{Q_{\mathrm{e}}}{C_{\mathrm{e}}}=\frac{\left(Q_{\max }-Q_{\mathrm{e}}\right)}{K_{\mathrm{d}}}
$$

where $K_{\mathrm{d}}[\mu \mathrm{mol} / \mathrm{L}]$ is the equilibrium dissociation constant, $Q_{\max }[\mu \mathrm{mol} / \mathrm{g}]$ is the apparent maximum adsorption amount, $Q_{\mathrm{e}}[\mu \mathrm{mol} / \mathrm{g}]$ is the equilibrium adsorption amount of $\mathrm{MIP}_{\mathrm{RhB}}-\mathrm{PPy} / \mathrm{TiO}_{2}$ for $\mathrm{RhB}$, and $C_{\mathrm{e}}[\mu \mathrm{mol} / \mathrm{L}]$ is the equilibrium concentration of $\mathrm{RhB}$. 


\subsubsection{Selectivity experiments}

In order to examine the recognition selectivity of $\mathrm{MIP}_{\mathrm{RhB}}-\mathrm{PPy} / \mathrm{TiO}_{2}$ towards $\mathrm{RhB}, \mathrm{Rh} 6 \mathrm{G}$ and $\mathrm{MB}$ are selected as competitive substances. The size and structure of $\mathrm{Rh} 6 \mathrm{G}$ are quite analogous to $\mathrm{RhB}$. The chemical structure of $\mathrm{MB}$ and $\mathrm{RhB}$ has certain difference. The structures of $\mathrm{RhB}, \mathrm{Rh} 6 \mathrm{G}$ and $\mathrm{MB}$ were shown in Figure 1.

The equilibrium adsorption amount of $\mathrm{MIP}_{\mathrm{RhB}}-\mathrm{PPy} /$ $\mathrm{TiO}_{2}$ and NIP-PPy/TiO ${ }_{2}$ for RhB and the competition species were calculated as above. The distribution coefficients $\left(K_{\mathrm{D}}, \mathrm{L} / \mathrm{g}\right)$ for $\mathrm{RhB}, \mathrm{Rh} 6 \mathrm{G}$ and $\mathrm{MB}$ were calculated according to Equation (4):

$K_{\mathrm{D}}=\frac{Q_{\mathrm{e}}}{C_{\mathrm{e}}}$

where $Q_{\mathrm{e}}[\mu \mathrm{mol} / \mathrm{g}]$ is the equilibrium adsorption amount, and $C_{\mathrm{e}}[\mu \mathrm{mol} / \mathrm{L}]$ is the equilibrium concentration.

The selectivity coefficients $(\alpha)$ of $\mathrm{MIP}_{\mathrm{RhB}}-\mathrm{PPy} / \mathrm{TiO}_{2}$ and NIP-PPy/ $/ \mathrm{TiO}_{2}$ for $\mathrm{RhB}$ relative to the competition species were obtained from Equation (5):

$\alpha=\frac{K_{\mathrm{Di}}}{K_{\mathrm{Dj}}}$

where $i$ and $j$ represent the template and competition species, respectively.

A relative selectivity coefficient $\left(\alpha^{\prime}\right)$ can be defined as Equation (6):

$\alpha^{\prime}=\frac{\alpha_{\mathrm{MIP}}}{\alpha_{\mathrm{NIP}}}$

where $\alpha_{\mathrm{MIP}}$ and $\alpha_{\mathrm{NIP}}$ are selectivity coefficients of $\mathrm{MIP}_{\mathrm{RhB}}-\mathrm{PPy} / \mathrm{TiO}_{2}$ and NIP-PPy/TiO ${ }_{2}$ for RhB relative to the competition species, respectively.
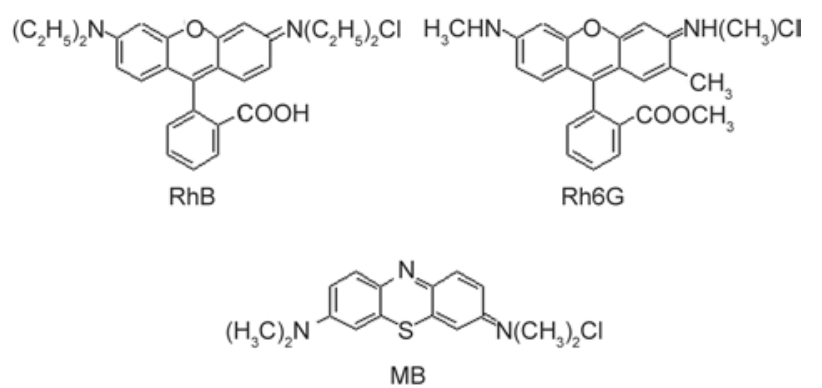

Figure 1. The structures of RhB, Rh6G and MB

\subsection{Photocatalytic activity measurement}

Photocatalytic activities of $\mathrm{MIP} \mathrm{RhB}_{-}-\mathrm{PPy} / \mathrm{TiO}_{2}$ and NIP-PPy $/ \mathrm{TiO}_{2}$ nanocomposites were evaluated by photocatalytic degradation of RhB, Rh6G and MB aqueous solution under visible light irradiation, respectively. Experiments were carried out in a Pyrex photocatalytic reactor under $300 \mathrm{~W}$ Xe lamp with a $400 \mathrm{~nm}$ cutoff filter which was used as the visible light source. $\mathrm{MIP}_{\mathrm{RhB}}-\mathrm{PPy} / \mathrm{TiO}_{2}(0.1 \mathrm{~g})$ or NIP-PPy/TiO 2 $(0.1 \mathrm{~g})$ nanocomposites were dispersed into $\mathrm{RhB}$ solution $\left(100 \mathrm{~mL}, 10 \mathrm{mg} \cdot \mathrm{L}^{-1}\right)$, respectively, then stirred in dark for $50 \mathrm{~min}$ to reach the adsorption-desorption equilibrium and the concentration of the $\mathrm{RhB}$ was determined as the initial concentration $C_{0}$. During irradiation, about $4.0 \mathrm{~mL}$ of the suspension continually was taken from the reaction cell every $20 \mathrm{~min}$. The nanocomposites and the RhB solution were separated with acentrifuge. The RhB concentration was also analyzed through a UV-vis spectrophotometer. The degradation of $\mathrm{Rh} 6 \mathrm{G}$ and $\mathrm{MB}$ aqueous solution were tested by using the same method.

\section{Results and discussion}

\subsection{Preparing processes of $\mathrm{MIP}_{\mathrm{RhB}}-\mathrm{PPy} / \mathrm{TiO}_{2}$}

The possible preparation protocol of $\mathrm{MIP}_{\mathrm{RhB}}-\mathrm{PPy} /$ $\mathrm{TiO}_{2}$ nanocomposites is shown in Figure 2. It is of obvious importance that the functional monomers strongly interact with the template and form stable host-guest complexes prior to polymerization. From the structure of RhB shown in Figure 2, the epoxy group and a carboxyl group of $\mathrm{RhB}$ can interact with the secondary amines group of pyrrole via the hydrogen bonds to form a stable host-guest complex. The existence of such a complex leads to the formation of well-defined specific binding sites in imprinted layer of $\mathrm{TiO}_{2}$. Subsequently, in situ polymerization occurs with the oxidizer of $\mathrm{FeCl}_{3} \cdot 6 \mathrm{H}_{2} \mathrm{O}$, and $\mathrm{PPy}$ layer gradually grows on the surface of $\mathrm{TiO}_{2}$ granules and extends to the interparticle space. Ultimately, the molecularly imprinted $\mathrm{PPy} / \mathrm{TiO}_{2}$ particles were washed by ammonia aqueous solution to remove $\mathrm{RhB}$ and leave imprinted cavities.

\subsection{Charaterization of $\mathrm{MIP}_{\mathrm{RhB}}-\mathrm{PPy} / \mathrm{TiO}_{2}$}

XRD patterns of the $\mathrm{TiO}_{2}$ and $\mathrm{MIP}_{\mathrm{RhB}}-\mathrm{PPy} / \mathrm{TiO}_{2}$ photocatalysts are shown in Figure 3. In comparison with $\mathrm{TiO}_{2}, \mathrm{MIP}_{\mathrm{RhB}}-\mathrm{PPy} / \mathrm{TiO}_{2}$ has no new diffraction peaks in the XRD pattern due to the amorphous imprinted layer. The average crystallite size of each sample is estimated by using the Scherrer formula, which is defined as Equation (7): 


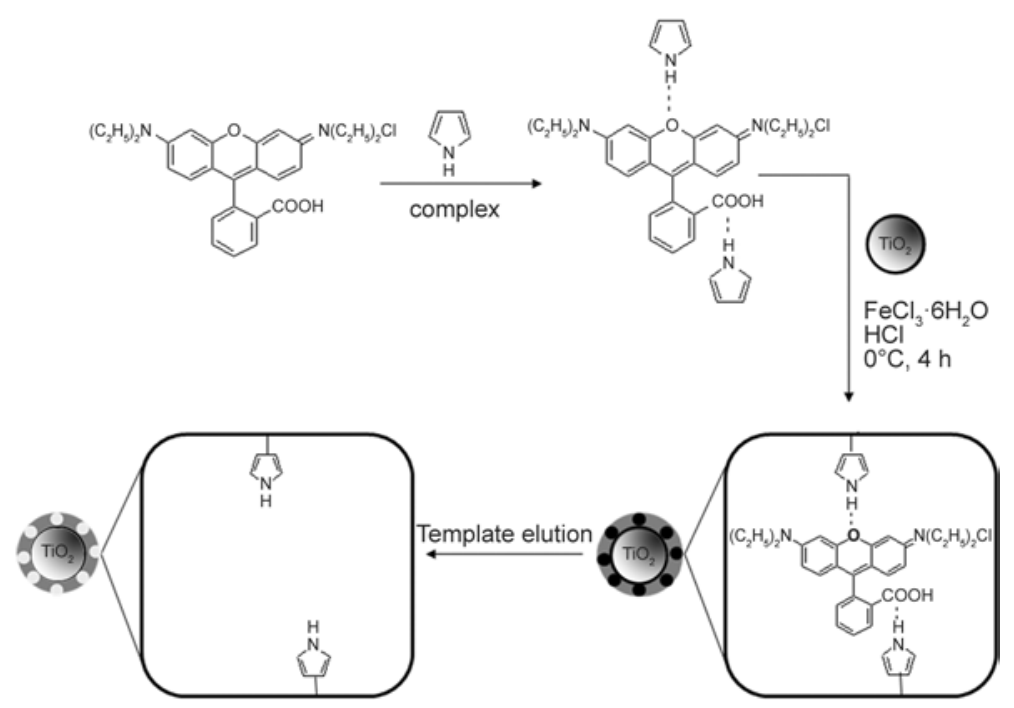

Figure 2. The preparation protocol of $\mathrm{MIP}_{\mathrm{RhB}}-\mathrm{PPy} / \mathrm{TiO}_{2}$

$D_{\text {Scherrer }}=\frac{K \lambda}{\beta \cos \theta}$

where $K$ is the Scherrer constant $(K=0.89), \lambda$ is the wavelength of the $X$-ray radiation $(\lambda=0.154056 \mathrm{~nm})$,

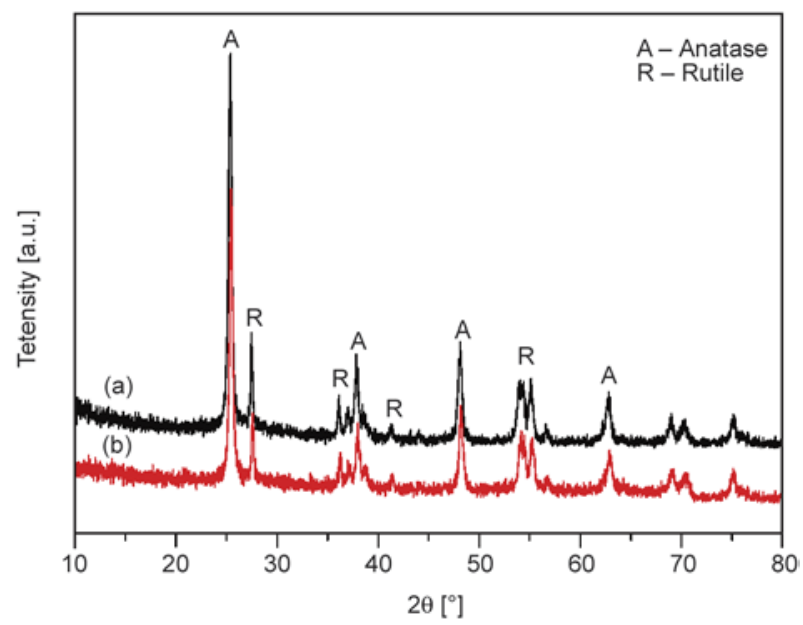

Figure 3. XRD patterns of: (a) $\mathrm{TiO}_{2}$ and (b) $\mathrm{MIP}_{\mathrm{RhB}}-\mathrm{PPy} /$ $\mathrm{TiO}_{2}$

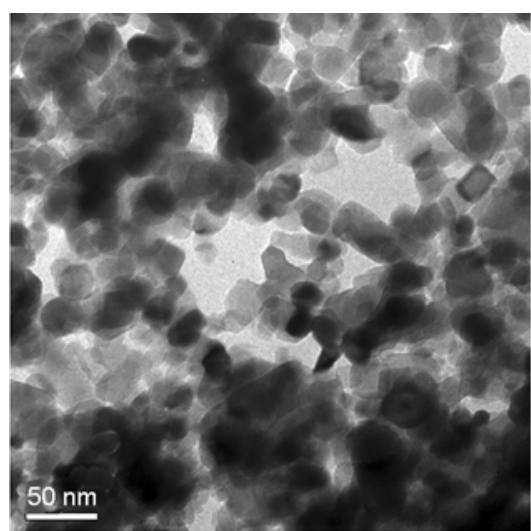

a)

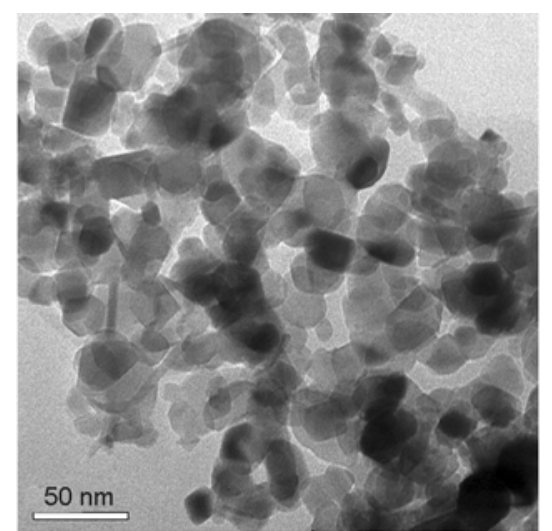

b) $\beta$ is the line width at half-maximum height of the most intense peak and $\theta$ is the diffraction angle.

The mean size of $\mathrm{TiO}_{2}$ and $\mathrm{MIP}_{\mathrm{RhB}}-\mathrm{PPy} / \mathrm{TiO}_{2}$ photocatalysts can be estimated to be 19.70 and $21.05 \mathrm{~nm}$, respectively. The result indicates that size of $\mathrm{MIP}_{\mathrm{RhB}^{-}}$ $\mathrm{PPy} / \mathrm{TiO}_{2}$ is a little bit larger than that of $\mathrm{TiO}_{2}$. It can be attributed to the thin imprinted layer which coating on the surface of $\mathrm{TiO}_{2}$.

The TEM images of $\mathrm{TiO}_{2}$ and $\mathrm{MIP}_{\mathrm{RhB}}-\mathrm{PPy} / \mathrm{TiO}_{2}$ are given in Figure $4 a$ and $4 b$, respectively. It can be confirmed that the morphology of $\mathrm{MIP}_{\mathrm{RhB}}-\mathrm{PPy} / \mathrm{TiO}_{2}$ does not differ much from that of $\mathrm{TiO}_{2}$. The mean size of $\mathrm{MIP}_{\mathrm{RhB}}-\mathrm{PPy} / \mathrm{TiO}_{2}$ and $\mathrm{TiO}_{2}$ are similar by comparing Figure $4 \mathrm{a}$ and $4 \mathrm{~b}$, which indicating that the imprinted layer is very thin. Figure $4 \mathrm{a}$ and $4 \mathrm{~b}$ also reveals that $\mathrm{TiO}_{2}$ are aggregated, and the $\mathrm{MIP}_{\mathrm{RhB}}{ }^{-}$ $\mathrm{PPy} / \mathrm{TiO}_{2}$ alleviates the aggregation. The aggregation of $\mathrm{TiO}_{2}$ could be attributed to high surface energy of the nanoparticles, and the repulsion force produced by the imprinted layer of the $\mathrm{TiO}_{2}$ can

Figure 4. TEM images of: (a) $\mathrm{TiO}_{2}$ and (b) (c) $\mathrm{MIP}_{\mathrm{RhB}}-\mathrm{PPy} / \mathrm{TiO}_{2}$ 
inhibit the aggregation of the $\mathrm{MIP}_{\mathrm{RhB}}-\mathrm{PPy} / \mathrm{TiO}_{2}$ nanocomposites. Figure $4 \mathrm{c}$ is the HR-TEM image of $\mathrm{MIP}_{\mathrm{RhB}}-\mathrm{PPy} / \mathrm{TiO}_{2}$. It shows the surface of $\mathrm{MIP}_{\mathrm{RhB}^{-}}$ $\mathrm{PPy} / \mathrm{TiO}_{2}$ nanocomposites is relatively rough, suggesting the formation of imprinting layer with a thickness of about $2 \mathrm{~nm}$. The results are in good agreement with the XRD patterns.

The BET specific surface areas of $\mathrm{MIP}_{\mathrm{RhB}}-\mathrm{PPy} / \mathrm{TiO}_{2}$ and NIP-PPy/TiO 2 were measured as 60.1 and $55.3 \mathrm{~m}^{2} / \mathrm{g}$, respectively. The BET specific surface area of $\mathrm{MIP}_{\mathrm{RhB}}-\mathrm{PPy} / \mathrm{TiO}_{2}$ and NIP-PPy/TiO 2 is larger than that of $\mathrm{TiO}_{2}\left(49.6 \mathrm{~m}^{2} / \mathrm{g}\right)$. It indicated that the dispersion of $\mathrm{MIP}_{\mathrm{RhB}}-\mathrm{PPy} / \mathrm{TiO}_{2}$ is better than that of $\mathrm{TiO}_{2}$. The BET specific surface area of $\mathrm{MIP}_{\mathrm{RhB}^{-}}$ $\mathrm{PPy} / \mathrm{TiO}_{2}$ is a little greater than that of NIP-PPy/ $\mathrm{TiO}_{2}$, it may be due to the initial molar ratio of PPy to $\mathrm{TiO}_{2}$ which is 1:100. The amount of PPy is small, therefore, the imprinted cavities on the surface of $\mathrm{MIP}_{\mathrm{RhB}}-\mathrm{PPy} / \mathrm{TiO}_{2}$ play a tenuous role in improving the specific surface area.

\subsection{Optical absorption properties}

The optical properties of $\mathrm{TiO}_{2}, \mathrm{MIP}_{\mathrm{RhB}}-\mathrm{PPy} / \mathrm{TiO}_{2}$ and NIP-PPy $/ \mathrm{TiO}_{2}$ were measured by UV-vis diffuse reflectance spectroscopy (DRS). Figure 5 shows the DRS of the $\mathrm{TiO}_{2}, \mathrm{MIP}_{\mathrm{RhB}}-\mathrm{PPy} / \mathrm{TiO}_{2}$ and NIP-PPy/ $\mathrm{TiO}_{2}$. It can be seen that the absorption of $\mathrm{MIP}_{\mathrm{RhB}^{-}}$ $\mathrm{PPy} / \mathrm{TiO}_{2}$ and NIP-PPy/TiO 2 are much enhanced in the whole range of visible region compared with $\mathrm{TiO}_{2}$. It is well known that the $\mathrm{TiO}_{2}$ itself can not been excited by visible light. The possible explanation for this is that some synergic effect between PPy and $\mathrm{TiO}_{2}$ which may induce efficiency of charge separation and PPy plays a role as photosensitizer in the nanocomposites. A classical Tauc method is employed

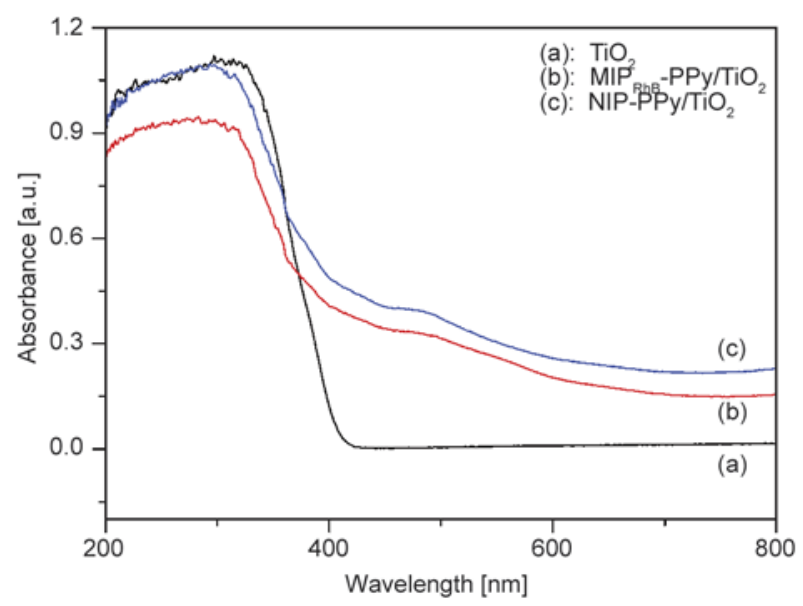

Figure 5. UV-vis diffuse reflectance spectra of $\mathrm{TiO}_{2}, \mathrm{MIP}_{\mathrm{RhB}}-$ $\mathrm{PPy} / \mathrm{TiO}_{2}$ and NIP-PPy/TiO 2 to estimate the band gap enegy $\left(E_{\mathrm{g}}\right)$ of a semiconductor according to the Equation (8):

$\alpha E_{\text {photon }}=K\left(E_{\text {photon }}-E_{\mathrm{g}}\right)^{\mathrm{n} / 2}$

where $K$ is absorption constants for indirect transitions, $\alpha$ is the absorption coefficient, $E_{\text {photon }}$ is the discrete photo-energy and $E_{\mathrm{g}}$ is the band gap energy. Among them, $n$ depends on the characteristics of the transition in a semiconductor (direct transition $n=1$ and indirect transition $n=4$ ). For $\mathrm{TiO}_{2}$, the value of $n$ is 1 .

The $E_{\mathrm{g}}$ of $\mathrm{MIP} \mathrm{RhB}_{-} \mathrm{PPy} / \mathrm{TiO}_{2}$ and NIP-PPy/TiO 2 are calculated to be 2.91 , and $2.95 \mathrm{eV}$, respectively. They are less than that of $\mathrm{TiO}_{2}$ (about $3.15 \mathrm{eV}$ ). The above results reveal that the absorption edges of $\mathrm{MIP}_{\mathrm{RhB}}-\mathrm{PPy} / \mathrm{TiO}_{2}$ lie in the visible region, so the nanocomposites can be excited to produce more electron-hole pairs under visible light irradiation, which could result in higher photocatalytic.

\subsection{Photoelectrochemical properties}

The transient photocurrent responses of $\mathrm{TiO}_{2}$ and $\mathrm{MIP}_{\mathrm{RhB}}-\mathrm{PPy} / \mathrm{TiO}_{2}$ were recorded for several on-off cycles of visible light irradiation. As shown in Figure 6, the current responses on both the $\mathrm{TiO}_{2}$ and $\mathrm{MIP}_{\mathrm{RhB}}-\mathrm{PPy} / \mathrm{TiO}_{2}$ in the dark are very low. When the irradiation was on, the electrons and holes were generated, therefore the current responses were drastically increased and the photocurrent came back to the original value as soon as the irradiation of light on the photoanode was stopped. In comparison with $\mathrm{TiO}_{2}, \mathrm{MIP}_{\mathrm{RhB}}-\mathrm{PPy} / \mathrm{TiO}_{2}$ exhibited more intensive photocurrent responses, which indicated that $\mathrm{MIP}_{\mathrm{RhB}^{-}}$ $\mathrm{PPy} / \mathrm{TiO}_{2}$ can effectively reduce more the recombi-

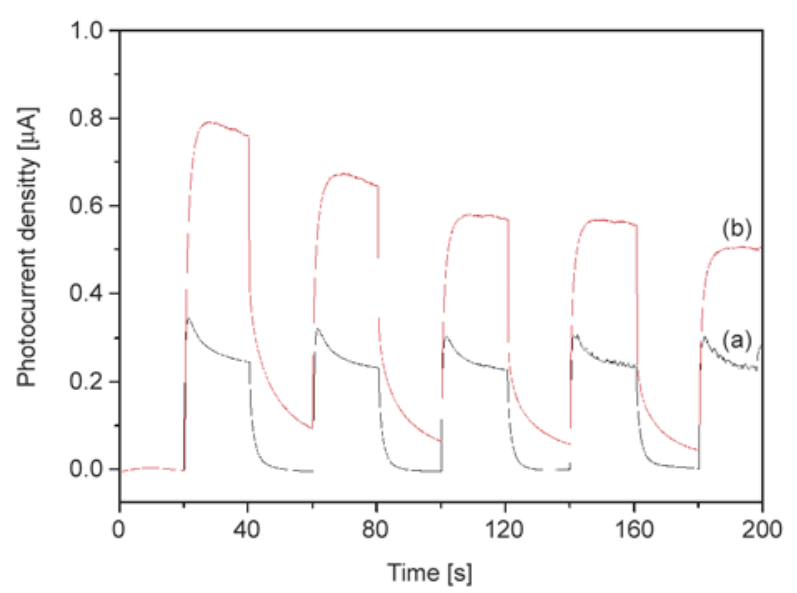

Figure 6. Transient photocurrent responses of: (a) $\mathrm{TiO}_{2}$ and (b) $\mathrm{MIP}_{\mathrm{RhB}}-\mathrm{PPy} / \mathrm{TiO}_{2}$ 
nation of photogenerated electrons and holes, and produce longer living photogenerated carriers than that of $\mathrm{TiO}_{2}$. Therefore, $\mathrm{MIP}_{\mathrm{RhB}}-\mathrm{PPy} / \mathrm{TiO}_{2}$ is expected to exhibit an improved photocatalytic activity for $\mathrm{RhB}$ degradation under visible light irradiation.

\subsection{Adsorption properties of the nanocomposites \\ 3.5.1. Adsorption kinetics}

The adsorption kinetics curve of $\mathrm{MIP}_{\mathrm{RhB}}-\mathrm{PPy} / \mathrm{TiO}_{2}$ towards template $\mathrm{RhB}$ is provided in Figure 7. As seen in this figure, a fast initial adsorption of $\mathrm{RhB}$ by the $\mathrm{MIP}_{\mathrm{RhB}}-\mathrm{PPy} / \mathrm{TiO}_{2}$ was observed within the first $20 \mathrm{~min}$, followed by a slow increase of the adsorption amount till the adsorption equilibrium. The equilibrium time is less than $50 \mathrm{~min}$. It is reasonable to assume that the surface of $\mathrm{MIP}_{\mathrm{RhB}}-\mathrm{PPy} / \mathrm{TiO}_{2}$ has much imprinted cavities, the template RhB was easy to enter into the cavities and bind with the recognition sites. When the recognition sites were filled up, the rate of adsorption dropped significantly and adsorption process achieved equilibrium gradually. In order to investigate the underlying mechanism of the adsorption process, the kinetic data obtained were analyzed using pseudo-first-order rate equation (Equation (9)) and pseudo-second-order rate equation (Equation (10)):

$$
\log \left(Q_{\mathrm{e}}-Q_{\mathrm{t}}\right)=\log Q_{\mathrm{e}}-\frac{k_{1} t}{2.303}
$$

$\frac{1}{Q_{\mathrm{t}}}=\frac{1}{k_{2} Q_{\mathrm{e}}^{2}}+\frac{t}{Q_{\mathrm{e}}}$

where $Q_{\mathrm{e}}[\mu \mathrm{mol} / \mathrm{g}]$ and $Q_{\mathrm{t}}[\mu \mathrm{mol} / \mathrm{g}]$ are the adsorption amount at equilibrium and time $t[\mathrm{~min}]$, respec-

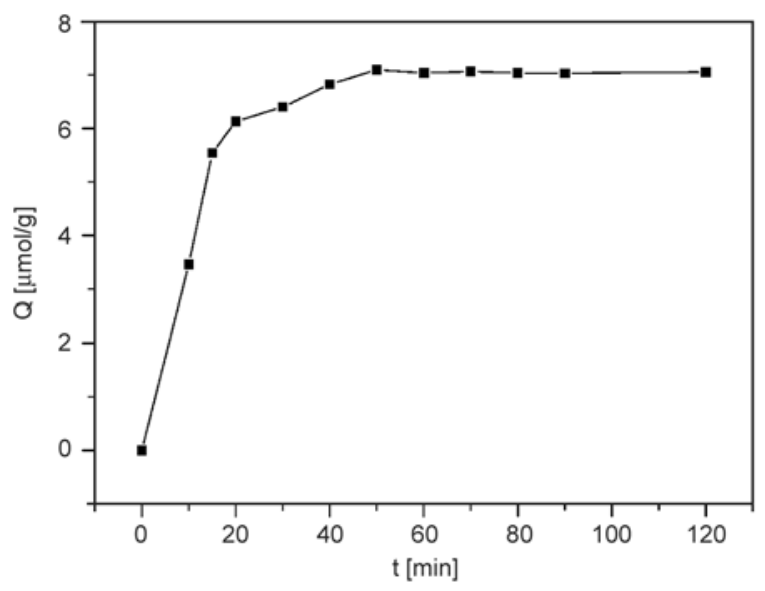

Figure 7. Adsorption kinetics curve of $\mathrm{MIP}_{\mathrm{RhB}}-\mathrm{PPy} / \mathrm{TiO}_{2}$ for RhB
Table 1. Adsorption kinetic constants for the pseudo-firstorder rate equation and pseudo-second-order rate equation

\begin{tabular}{|l|c|l|c|}
\hline Constants & $\begin{array}{c}\text { Pseudo-first- } \\
\text { order } \\
\text { equation }\end{array}$ & \multicolumn{1}{|c|}{ Constants } & $\begin{array}{c}\text { Pseudo- } \\
\text { second-order } \\
\text { equation }\end{array}$ \\
\hline$Q_{\mathrm{e}, \mathrm{c}}[\mu \mathrm{mol} / \mathrm{g}]$ & 2.876 & $Q_{\mathrm{e}, \mathrm{c}}[\mu \mathrm{mol} / \mathrm{g}]$ & 7.537 \\
\hline$Q_{\mathrm{exp}}[\mu \mathrm{mol} / \mathrm{g}]$ & 7.095 & $\left.\left.Q_{\mathrm{exp}}\right] \mu \mathrm{mol} / \mathrm{g}\right]$ & 7.095 \\
\hline$k_{1}\left[\mathrm{~min}^{-1}\right]$ & 0.0456 & $k_{2}[\mathrm{~g} /(\mu \mathrm{mol} \cdot \mathrm{min})]$ & 0.0228 \\
\hline$R^{2}$ & 0.8107 & $R^{2}$ & 0.9947 \\
\hline
\end{tabular}

tively, $k_{1}\left(\min ^{-1}\right)$ and $k_{2}(\mathrm{~g} /(\mu \mathrm{mol} \cdot \mathrm{min}))$ are pseudofirst-order and pseudo-second-order rate constants of adsorption, respectively.

The adsorption kinetic constants for the pseudofirst-order rate equation and pseudo-second-order rate equation are listed in Table 1. As shown in Table 1, the correlation coefficient for the pseudosecond-order rate equation $\left(R^{2}=0.9947\right)$ was higher than that of pseudo-first-order rate equation $\left(R^{2}=\right.$ $0.8107)$. Moreover, the calculated equilibrium adsorption amount of $\mathrm{MIP}_{\mathrm{RhB}}-\mathrm{PPy} / \mathrm{TiO}_{2}$ is $7.537 \mu \mathrm{mol} / \mathrm{g}$, which is consistent with the experimental data (7.095 $\mu \mathrm{mol} / \mathrm{g}$ ). Therefore, the adsorption behavior of $\mathrm{MIP}_{\mathrm{RhB}}-\mathrm{PPy} / \mathrm{TiO}_{2}$ for $\mathrm{RhB}$ belonged to the pseudosecond-order rate equation and the adsorption process was a chemical process.

\subsubsection{Adsorption isotherms}

The adsorption isotherms of $\mathrm{MIP}_{\mathrm{RhB}}-\mathrm{PPy} / \mathrm{TiO}_{2}$ and NIP-PPy $/ \mathrm{TiO}_{2}$ for RhB are illustrated in Figure 8a. As shown in this figure, the adsorption amount of the $\mathrm{MIP}_{\mathrm{RhB}}-\mathrm{PPy} / \mathrm{TiO}_{2}$ and NIP-PPy/TiO ${ }_{2}$ increased gradually with the increase of concentration of $\mathrm{RhB}$ in the initial solution, and ultimately inclined to reach a stable value, the adsorption reached saturation. In addition, it also could be found that $\mathrm{MIP}_{\mathrm{RhB}}-\mathrm{PPy} /$ $\mathrm{TiO}_{2}$ had much higher adsorption amount than that of NIP-PPy $/ \mathrm{TiO}_{2}$ at either low or high concentration. The above facts indicated that the non-selective physical adsorption occurred between NIP-PPy $/ \mathrm{TiO}_{2}$ and $\mathrm{RhB}$. In contrast, the $\mathrm{MIP}_{\mathrm{RhB}}-\mathrm{PPy} / \mathrm{TiO}_{2}$ had generated specific recognition sites in imprinting cavities and exhibited higher adsorption capacity for $\mathrm{RhB}$. Due to the adsorption capacity has much influence on the degradation behavior of organic pollutants, it is hoped that the $\mathrm{MIP}_{\mathrm{RhB}}-\mathrm{PPy} / \mathrm{TiO}_{2}$ show higher photocatalytic selectivity towards $\mathrm{RhB}$ than that of NIP-PPy/TiO 2 .

In general, Scatchard analysis was used to evaluate the binding affinity and the theoretical binding site 

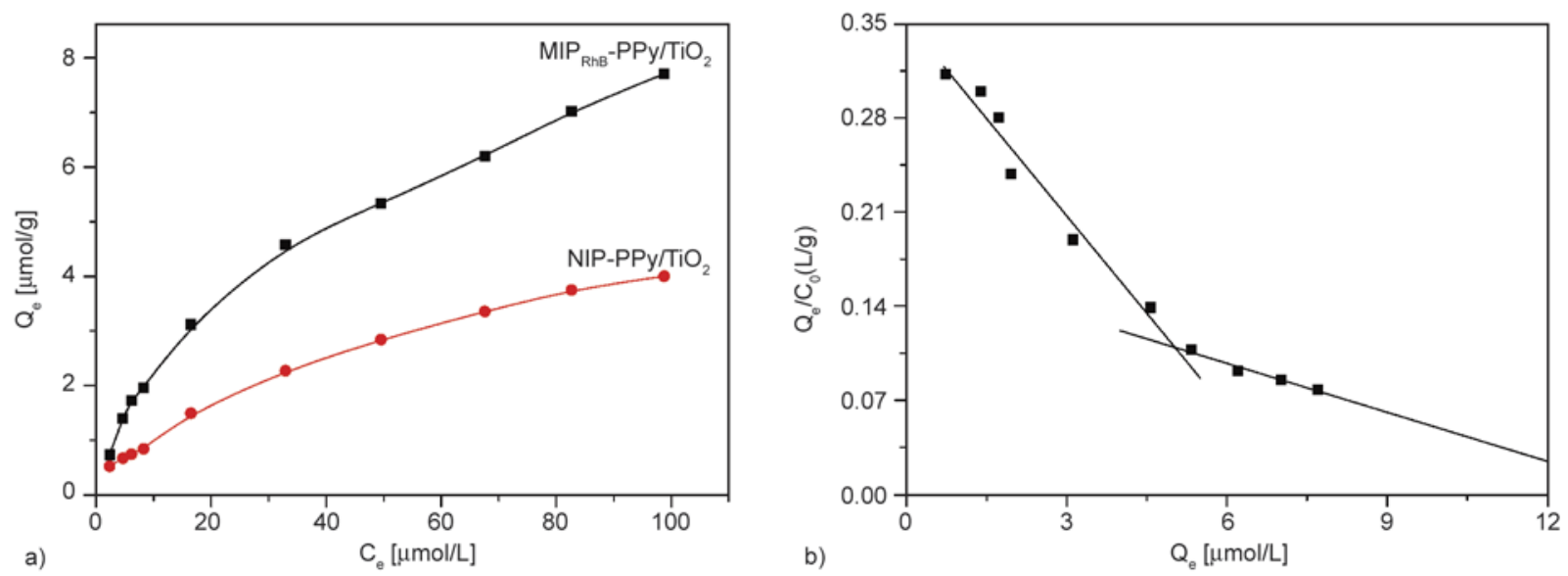

Figure 8. (a) Adsorption isotherms of $\mathrm{MIP}_{\mathrm{RhB}}-\mathrm{PPy} / \mathrm{TiO}_{2}$ and $\mathrm{NIP}-\mathrm{PPy} / \mathrm{TiO}_{2}$ for $\mathrm{RhB}$ (b) Scatchard plot of the adsorption of $\mathrm{MIP}_{\mathrm{RhB}}-\mathrm{PPy} / \mathrm{TiO}_{2}$ for $\mathrm{RhB}$

Table 2. The results of the Scatchard analysis

\begin{tabular}{|l|c|c|c|c|}
\hline \multicolumn{1}{|c|}{ Binding site } & Linear equation & $\begin{array}{c}\mathbf{K}_{\mathbf{d}} \\
{[\boldsymbol{\mu \mathbf { m o l } / \mathbf { L } ]}}\end{array}$ & $\begin{array}{c}\mathbf{Q}_{\max } \\
{[\mu \mathbf{m o l} / \mathbf{g}]}\end{array}$ & $\mathbf{R}^{\mathbf{2}}$ \\
\hline Higher affinity site & $Q_{\mathrm{e}} / C_{0}=-0.0482 Q_{\mathrm{e}}+0.3517$ & 20.75 & 7.41 & 0.9490 \\
\hline Lower affinity site & $Q_{\mathrm{e}} / C_{0}=-0.0121 Q_{\mathrm{e}}+0.1703$ & 82.64 & 14.07 & 0.9492 \\
\hline
\end{tabular}

number for template of the molecularly imprinted material. Figure $8 \mathrm{~b}$ shows the Scatchard plot of the adsorption of $\mathrm{MIP}_{\mathrm{RhB}}-\mathrm{PPy} / \mathrm{TiO}_{2}$ for $\mathrm{RhB}$. As seen in this figure, there were two distinct linear sections in the plot. It suggests that there exist two types of binding sites in the imprinted layer in respect to the adsorption for RhB: one was of high selectivity or affinity with a high binding energy, and the other was of low affinity with a low binding energy. From the slopes and intercepts of the two straight lines, the $K_{\mathrm{d}}$ and $Q_{\max }$ values can be calculated, and the results are listed in Table 2.

\subsubsection{Adsorption selectivity}

Figure 9 shows the adsorption amount of $\mathrm{MIP}_{\mathrm{RhB}^{-}}$ $\mathrm{PPy} / \mathrm{TiO}_{2}$ and NIP-PPy/TiO ${ }_{2}$ for RhB, Rh6G and $\mathrm{MB}$, respectively. The distribution coefficient $\left(K_{\mathrm{D}}\right)$, selectivity coefficient of the sorbent $(\alpha)$ and the relative selectivity coefficient $\left(\alpha^{\prime}\right)$ values were summarized in Table 3. From Figure 9, the adsorption amount of $\mathrm{MIP}_{\mathrm{RhB}}-\mathrm{PPy} / \mathrm{TiO}_{2}$ for $\mathrm{RhB}$ is higher than that for Rh6G and MB. Compared with $\mathrm{MB}$, the adsorption amount of $\mathrm{MIP}_{\mathrm{RhB}}-\mathrm{PPy} / \mathrm{TiO}_{2}$ for $\mathrm{Rh} 6 \mathrm{G}$ is higher, whereas the adsorption amount of NIP-PPy/

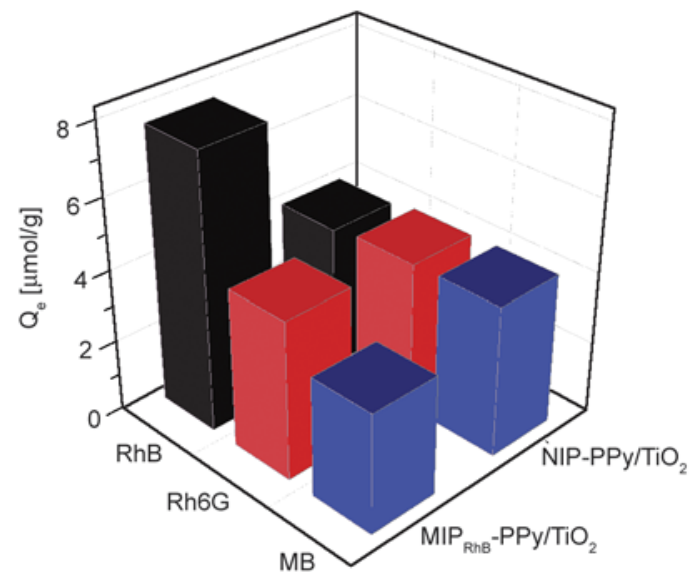

Figure 9. Adsorption amount of $\mathrm{MIP}_{\mathrm{RhB}}-\mathrm{PPy} / \mathrm{TiO}_{2}$ and NIP$\mathrm{PPy} / \mathrm{TiO}_{2}$ for $\mathrm{RhB}$, Rh6G and $\mathrm{MB}$

$\mathrm{TiO}_{2}$ for the three substrates was almost the same. This indicated that the imprinted cavities have been created in $\mathrm{MIP}_{\mathrm{RhB}}-\mathrm{PPy} / \mathrm{TiO}_{2}$ owing to the addition of template $\mathrm{RhB}$ during polymerization, and the binding abilities of $\mathrm{MIP}_{\mathrm{RhB}}-\mathrm{PPy} / \mathrm{TiO}_{2}$ for $\mathrm{RhB}$ is far stronger than that for Rh6G and MB. From the data shown in Table 3, the selectivity coefficients of $\mathrm{MIP}_{\mathrm{RhB}}-\mathrm{PPy} / \mathrm{TiO}_{2}$ for $\mathrm{RhB}$ relative to $\mathrm{Rh} 6 \mathrm{G}$ and $\mathrm{MB}$ are higher, 1.75 and 2.29, respectively. The selectiv-

Table 3 Distribution coefficient and selectivity coefficient data of $\mathrm{MIP}_{\mathrm{RhB}}-\mathrm{PPy} / \mathrm{TiO}_{2}$ and NIP-PPy/TiO 2

\begin{tabular}{|c|c|c|c|c|c|c|c|c|}
\hline \multirow{2}{*}{ Photocatalyst } & \multicolumn{2}{|c|}{$K_{D}[L / g]$} & \multirow{2}{*}{$\alpha$} & \multirow{2}{*}{$\alpha^{\prime}$} & \multicolumn{2}{|c|}{$K_{D}[L / g]$} & \multirow{2}{*}{$\alpha$} & \multirow{2}{*}{$\alpha^{\prime}$} \\
\hline & RhB & Rh6G & & & RhB & MB & & \\
\hline $\mathrm{MIP}_{\mathrm{RhB}}-\mathrm{PPy} / \mathrm{TiO}_{2}$ & 0.096 & 0.055 & 1.75 & 1.82 & 0.096 & 0.042 & 2.29 & 2.44 \\
\hline NIP-PPy $/ \mathrm{TiO}_{2}$ & 0.050 & 0.052 & 0.96 & & 0.050 & 0.053 & 0.94 & \\
\hline
\end{tabular}


ity coefficients of NIP-PPy/TiO 2 for $\mathrm{RhB}$ relative to Rh6G and $\mathrm{MB}$ are lower, 0.96 and 0.94 , respectively. This implies that the $\mathrm{MIP}_{\mathrm{RhB}}-\mathrm{PPy} / \mathrm{TiO}_{2}$ had higher adsorption selectivity for $\mathrm{RhB}$ over $\mathrm{Rh} 6 \mathrm{G}$ and $\mathrm{MB}$. The relative selectivity coefficients of $\mathrm{MIP}_{\mathrm{RhB}^{-}}$ $\mathrm{PPy} / \mathrm{TiO}_{2}$ for $\mathrm{RhB}$ relative to $\mathrm{Rh} 6 \mathrm{G}$ and $\mathrm{MB}$ are 1.82 and 2.44, respectively, which are greater than 1 and showed the $\mathrm{MIP}_{\mathrm{RhB}}-\mathrm{PPy} / \mathrm{TiO}_{2}$ had higher adsorption selectivity than that of the NIP-PPy/TiO 2 .

\subsection{Photocatalytic activity}

The photocatalytic activity of the $\mathrm{MIP}_{\mathrm{RhB}}-\mathrm{PPy} / \mathrm{TiO}_{2}$ and NIP-PPy/ $/ \mathrm{TiO}_{2}$ nanocomposites was measured by the degradation of $\mathrm{RhB}, \mathrm{Rh} 6 \mathrm{G}$ and $\mathrm{MB}$ aqueous solutions under visible light irradiation, respectively. As shown in Figure 10a, the $\mathrm{MIP}_{\mathrm{RhB}}-\mathrm{PPy} / \mathrm{TiO}_{2}$ photocatalysts exhibits the highest photocatalytic activity toward RhB. The degradation efficiency reaches $85 \%$ after 120 min irradiation being 2.1 times of that over NIP-PPy/TiO $2(40 \%)$, meanwhile, the degradation efficiency of Rh6G and $\mathrm{MB}$ over $\mathrm{MIP}_{\mathrm{RhB}}-\mathrm{PPy} / \mathrm{TiO}_{2}$ are $63 \%$ and $59 \%$, respectively. Figure 10b shows the time-dependent absorption spectra of RhB solution in the presence of $\mathrm{MIP}_{\mathrm{RhB}^{-}}$ $\mathrm{PPy} / \mathrm{TiO}_{2}$ microspheres. The maximum absorption of $\mathrm{RhB}$ suspension shifts from 553 to $522 \mathrm{~nm}$. Meanwhile, it can be seen obviously that the color of the $\mathrm{RhB}$ solution changes gradually from fuchsia to colorless after irradiation for $120 \mathrm{~min}$.

Figure 11 gives the kinetic data for the photodegradation of RhB, Rh6G and MB over different photocatalysts in the single systems, which clearly show that all the degradation processes follow a pseudo-

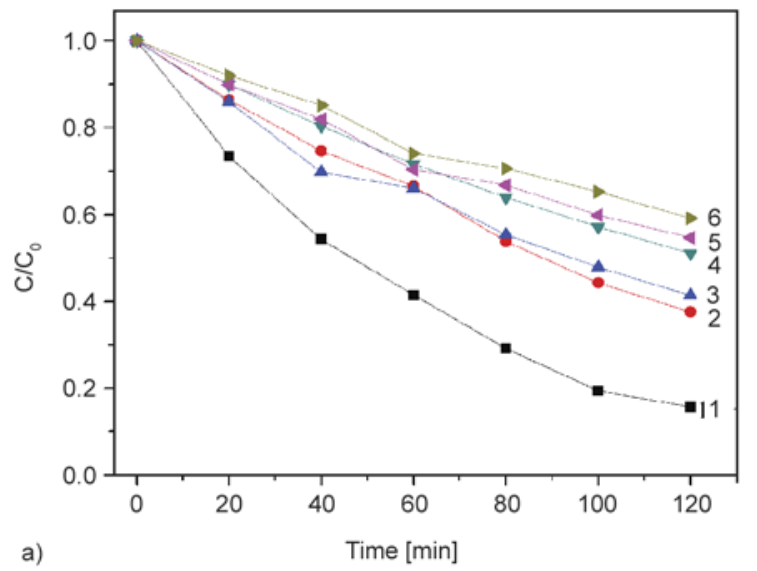

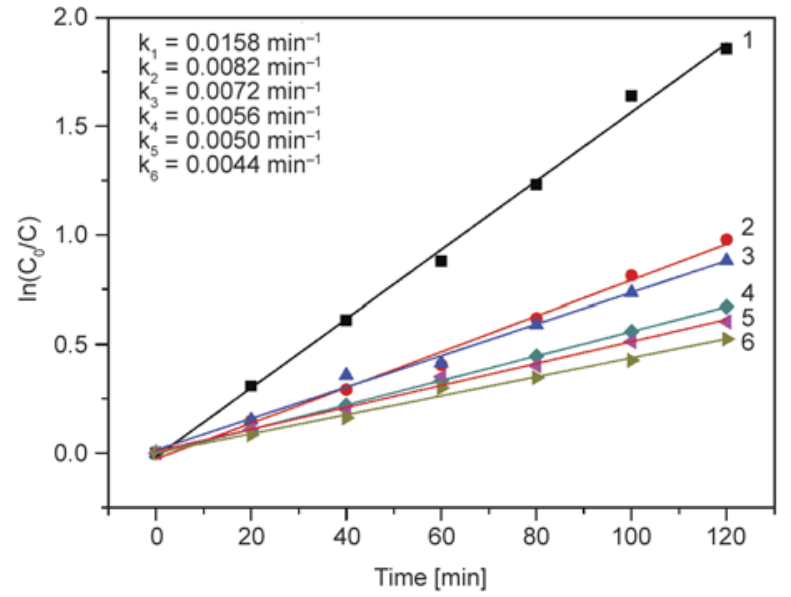

Figure 11. Kinetic datas for the degradation of $\mathrm{RhB}$ (1), Rh6G (2), MB (3) over $\mathrm{MIP}_{\mathrm{RhB}}-\mathrm{PPy} / \mathrm{TiO}_{2}$ and MB (4), Rh6G (5), RhB (6) over NIP-PPy/TiO 2

first-order kinetics, which was defined as Equation (11):

$\ln \left(\frac{C_{0}}{C}\right)=k t$

where $C_{0}[\mathrm{mg} / \mathrm{L}]$ and $C[\mathrm{mg} / \mathrm{L}]$ are the concentration of $\mathrm{RhB}, \mathrm{Rh} 6 \mathrm{G}$ or $\mathrm{MB}$ at $t=0$ [min] and instant $t$ [min], respectively, and $k\left[\mathrm{~min}^{-1}\right]$ is the apparent rate constant.

The values of the apparent rate constant $(k)$ of the pseudo-first-order reaction are listed in Figure 11. As seen in this figure, the $k$ value for the photodegradation of the targeted $\mathrm{RhB}$ over $\mathrm{MIP}_{\mathrm{RhB}}-\mathrm{PPy} / \mathrm{TiO}_{2}$ is $0.0158 \mathrm{~min}^{-1}$, being 3.6 times of that over NIP-PPy/ $\mathrm{TiO}_{2}\left(0.0044 \mathrm{~min}^{-1}\right)$, meanwhile, the $k$ values for the photodegradation of Rh6G and MB over $\mathrm{MIP}_{\mathrm{RhB}^{-}}$ $\mathrm{PPy} / \mathrm{TiO}_{2}$ are 0.0082 and $0.0072 \mathrm{~min}^{-1}$, being only

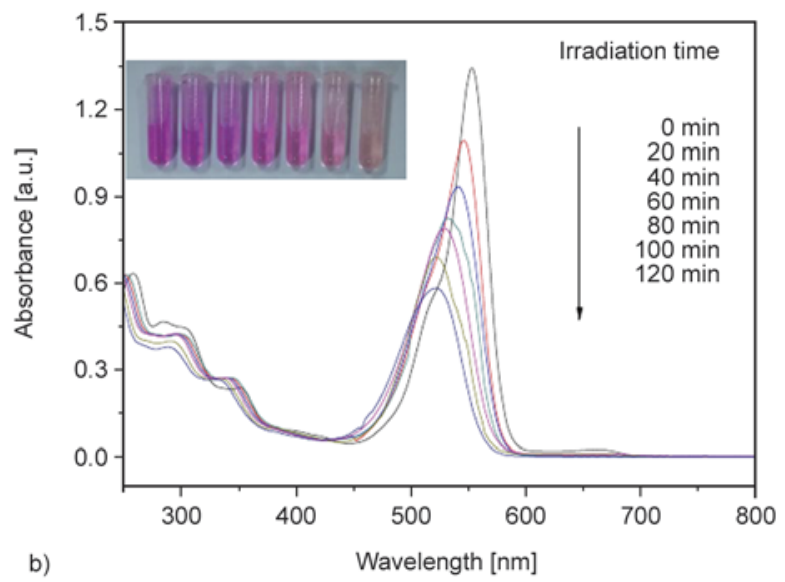

Figure 10. (a) The photodegradation of $\mathrm{RhB}$ (1), Rh6G (2), MB (3) over $\mathrm{MIP}_{\mathrm{RhB}}-\mathrm{PPy} / \mathrm{TiO}_{2}$ and $\mathrm{MB}$ (4), $\mathrm{Rh} 6 \mathrm{G}$ (5), RhB 6 ) over NIP-PPy $/ \mathrm{TiO}_{2}$ (b) temporal UV-vis absorption spectral changes during the photocatalytic degradation of $\mathrm{MIP}_{\mathrm{RhB}}-\mathrm{PPy} / \mathrm{TiO}_{2}$ toward $\mathrm{RhB}$ 


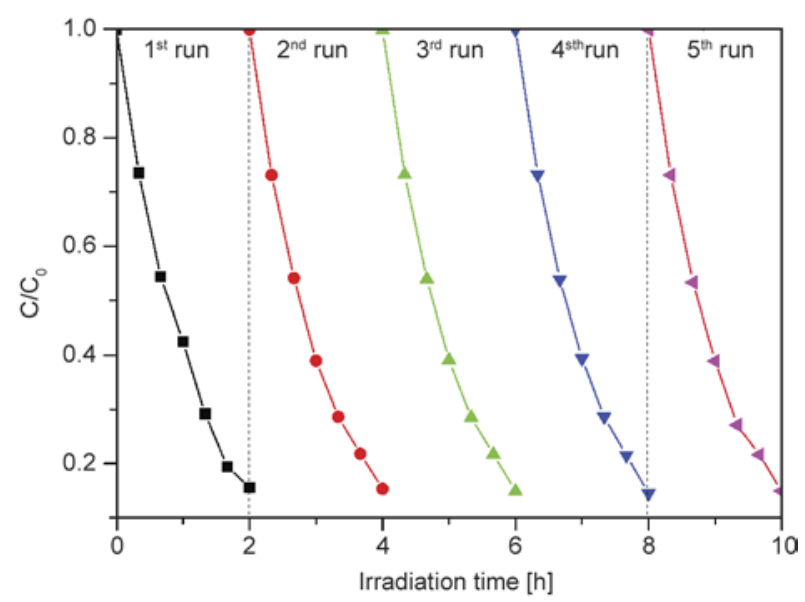

Figure 12. Results of cycling runs of $\mathrm{RhB}$ degradation over $\mathrm{MIP}_{\mathrm{RhB}}-\mathrm{PPy} / \mathrm{TiO}_{2}$

$52 \%$ and $46 \%$ of $\mathrm{RhB}$ over $\mathrm{MIP}_{\mathrm{RhB}}-\mathrm{PPy} / \mathrm{TiO}_{2}$, respectively. Moreover, the differences of the $k$ values for the photodegradation of $\mathrm{RhB}$, Rh6G and $\mathrm{MB}$ over NIP-PPy $/ \mathrm{TiO}_{2}$ are small. The possible explanation for this is that the $\mathrm{MIP}_{\mathrm{RhB}}-\mathrm{PPy} / \mathrm{TiO}_{2}$ and NIP$\mathrm{PPy} / \mathrm{TiO}_{2}$ with almost the same element are remarkably different in their space-structure, the nonselective physical adsorption occurred between $\mathrm{NIP}-\mathrm{PPy} / \mathrm{TiO}_{2}$ and $\mathrm{RhB}$. In contrast, the MIP $\mathrm{RhB}-\mathrm{PPy} /$ $\mathrm{TiO}_{2}$ adsorbed much more RhB than that of NIP$\mathrm{PPy} / \mathrm{TiO}_{2}$ since $\mathrm{MIP}_{\mathrm{RhB}}-\mathrm{PPy} / \mathrm{TiO}_{2}$ had generated specific recognition sites in imprinting cavities. Compared with NIP-PPy/TiO $2, \mathrm{MIP}_{\mathrm{RhB}}-\mathrm{PPy} / \mathrm{TiO}_{2}$ exhibited higher photocatalytic selectivity toward RhB.

Figure 12 shows the results of cycling runs of $\mathrm{RhB}$ degradation over $\mathrm{MIP}_{\mathrm{RhB}}-\mathrm{PPy} / \mathrm{TiO}_{2}$ The reusability and stability of $\mathrm{MIP}_{\mathrm{RhB}}-\mathrm{PPy} / \mathrm{TiO}_{2}$ was evaluated by the cycling runs for RhB photodegradation using the same imprinted photocatalyst. The degradation results were shown in Figure 12. It was found that the degradation ratios of $\mathrm{RhB}$ were almost kept stable around $80 \%$. The photocatalytic activity does not obviously decline in $\mathrm{RhB}$ degradation after five recycling runs. Therefore, it can be inferred that the $\mathrm{MIP}_{\mathrm{RhB}}-\mathrm{PPy} / \mathrm{TiO}_{2}$ has high reusability and stability.

\subsection{Photocatalytic mechanism}

The mechanism of the photocatalytic degradation of $\mathrm{RhB}$ over the $\mathrm{MIP}_{\mathrm{RhB}}-\mathrm{PPy} / \mathrm{TiO}_{2}$ nanocomposites was proposed. At first, the RhB molecules can be adsorbed onto the imprinted layer of $\mathrm{MIP}_{\mathrm{RhB}}-\mathrm{PPy} /$ $\mathrm{TiO}_{2}$ to form a moderately stable complex. When the $\mathrm{MIP}_{\mathrm{RhB}}-\mathrm{PPy} / \mathrm{TiO}_{2}$ nanocomposites are illuminated under visible light, the electrons of PPy can be excited from the highest occupied molecular orbital

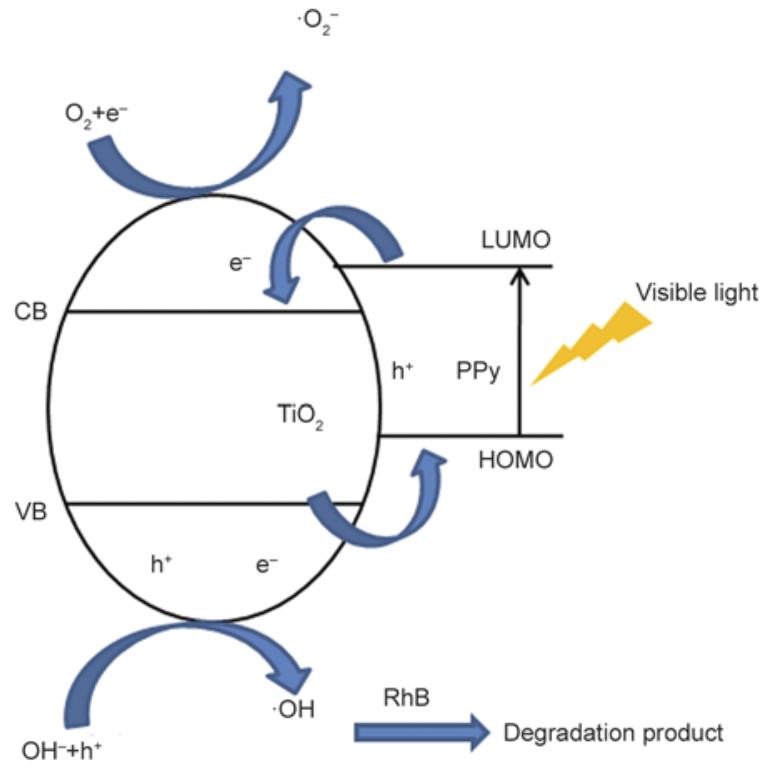

Figure 13. Scheme of the photocatalytic degradation of $\mathrm{RhB}$ over the $\mathrm{MIP}_{\mathrm{RhB}}-\mathrm{PPy} / \mathrm{TiO}_{2}$

(HOMO) to the lowest unoccupied molecular orbital (LUMO). Since the conduction band (CB) of $\mathrm{TiO}_{2}$ lies below the LUMO level of PPy, the excited electrons can be injected to $\mathrm{CB}$ of $\mathrm{TiO}_{2}$, while holes will be left in HOMO of PPy. The electrons in valence band (VB) of $\mathrm{TiO}_{2}$ can not only migrate to $\mathrm{CB}$ of $\mathrm{TiO}_{2}$, but also to the HOMO of PPy to recombine with the holes, and simultaneously, holes were generated in the $\mathrm{VB}$ of $\mathrm{TiO}_{2}$. Thus, more and more photogenerated electrons and holes form in $\mathrm{TiO}_{2}$ nanoparticles. The photo-generated electrons migrate easily to the catalysts surface to react with oxygen to generate superoxide radicals $\left(\cdot \mathrm{O}_{2}^{-}\right)$, and the positive charged holes $\left(\mathrm{h}^{+}\right)$can react with $\mathrm{OH}^{-}$or $\mathrm{H}_{2} \mathrm{O}$ to yield hydroxyl radicals $(\cdot \mathrm{OH})$. The resulting radicals are powerful enough to decompose oxidize $\mathrm{RhB}$ to the degradation products. The whole process can be clearly described as shown by Equation (12) and Figure 13 ([16, 34]).

$$
\begin{aligned}
\mathrm{MIP}_{\mathrm{RhB}}-\mathrm{PPy} / \mathrm{TiO}_{2}+ & \mathrm{RhB} \underset{\mathrm{MIP}_{\mathrm{RhB}}-\mathrm{PPy} / \mathrm{TiO}_{2}-\mathrm{RhB}}{\stackrel{\text { Adsorption }}{\longrightarrow}}
\end{aligned}
$$

\section{Conclusions}

A highly selective molecularly imprinted nanocomposites $\mathrm{MIP}_{\mathrm{RhB}}-\mathrm{PPy} / \mathrm{TiO}_{2}$ was successfully prepared by surface molecular imprinting technique with $\mathrm{RhB}$ as template molecule. $\mathrm{MIP}_{\mathrm{RhB}}-\mathrm{PPy} / \mathrm{TiO}_{2}$ exhibited obvious absorption under visible light. The transient photocurrent responses suggested that $\mathrm{MIP}_{\mathrm{RhB}}-\mathrm{PPy} /$ 
$\mathrm{TiO}_{2}$ could efficiently generate and separate of the electron-hole pairs. $\mathrm{MIP}_{\mathrm{RhB}}-\mathrm{PPy} / \mathrm{TiO}_{2}$ nanocomposites possessed strong affinity, high adsorption capacity, fast adsorption rate and excellent selectivity for RhB. In comparison with NIP-PPy/ $/ \mathrm{TiO}_{2}$, $\mathrm{MIP}_{\mathrm{RhB}}-\mathrm{PPy} / \mathrm{TiO}_{2}$ exhibited higher photocatalytic selectivity toward $\mathrm{RhB}$ under visible light. Therefore, the prepared nanocomposites $\mathrm{MIP}_{\mathrm{RhB}}-\mathrm{PPy} / \mathrm{TiO}_{2}$ has a promising perspective in industrial wastewater treatment.

\section{Acknowledgements}

This work was supported by the National Nature Science Foundation of China (No. 21206060)

\section{References}

[1] Asuha S., Zhou X. G., Zhao S.: Adsorption of methyl orange and $\mathrm{Cr}(\mathrm{VI})$ on mesoporous $\mathrm{TiO}_{2}$ prepared by hydrothermal method. Journal of Hazardous Materials, 181, 204-210 (2010).

DOI: 10.1016/j.jhazmat.2010.04.117

[2] Xu S. F., Li J. H., Chen L. X.: Molecularly imprinted core-shell nanoparticles for determination of trace atrazine by reversible addition-fragmentation chain transfer surface imprinting. Journal of Materials Chemistry, 21, 4346-4351 (2011).

DOI: $10.1039 / \mathrm{C} 0 J M 03593 \mathrm{~A}$

[3] Moon C-J., Lee J-H.: Use of curdlan and activated carbon composed adsorbents for heavy metal removal. Process Biochemistry, 40, 1279-1283 (2005). DOI: $10.1016 /$ j.procbio.2004.05.009

[4] Wang G. H., Xu L., Zhang J., Yin T., Han D.: Enhanced photocatalytic activity of $\mathrm{TiO}_{2}$ powders (P25) via calcination treatment. International Journal of Photoenergy, 2012, 265760/1-265760/9 (2012).

DOI: $10.1155 / 2012 / 265760$

[5] Bettinelli M., Dallacasa V., Falcomer D., Fornasiero P., Gombac V., Montini T., Romanò L., Speghini A.: Photocatalytic activity of $\mathrm{TiO}_{2}$ doped with boron and vanadium. Journal of Hazardous Materials, 146, 529534 (2007). DOI: 10.1016/j.jhazmat.2007.04.053

[6] Li X., Wang L., Lu X.: Preparation of silver-modified $\mathrm{TiO}_{2}$ via microwave-assisted method and its photocatalytic activity for toluene degradation. Journal of Hazardous Materials, 177, 639-647 (2010).

DOI: $10.1016 /$ j.jhazmat.2009.12.080

[7] Tian G., Pan K., Fu H., Jing L., Zhou W.: Enhanced photocatalytic activity of S-doped $\mathrm{TiO}_{2}-\mathrm{ZrO}_{2}$ nanoparticles under visible-light irradiation. Journal of Hazardous Materials, 166, 939-944 (2009).

DOI: $10.1016 /$ j.jhazmat.2008.11.090
[8] Liu D., Xiao P., Zhang Y., Garcia B. B., Zhang Q., Guo Q., Champion R., Cao G.: $\mathrm{TiO}_{2}$ nanotube arrays annealed in $\mathrm{N}_{2}$ for efficient lithium-ion intercalation. Journal of Physical Chemistry C, 112, 11175-11180 (2008). DOI: $10.1021 / j p 801300 j$

[9] Li Y., Guo M., Peng S., Lu G., Li S.: Formation of multilayer-eosin Y-sensitized $\mathrm{TiO}_{2}$ via $\mathrm{Fe}^{3+}$ coupling for efficient visible-light photocatalytic hydrogen evolution. International Journal of Hydrogen Energy, 34, 5629-5636 (2009). DOI: 10.1016/j.ijhydene.2009.05.100

[10] Xu S., Du A. J., Liu J., Ng J., Sun D. D.: Highly efficient $\mathrm{CuO}$ incorporated $\mathrm{TiO}_{2}$ nanotube photocatalyst for hydrogen production from water. International Journal of Hydrogen Energy, 36, 6560-6568 (2011). DOI: 10.1016/j.ijhydene.2011.02.103

[11] Shang X., Hu G., He C., Zhao J., Zhang F., Xu Y., Zhang Y., Li J., Chen J.: Regeneration of full-scale commercial honeycomb monolith catalyst $\left(\mathrm{V}_{2} \mathrm{O}_{5}-\mathrm{WO}_{3} /\right.$ $\mathrm{TiO}_{2}$ ) used in coal-fired power plant. Journal of Industrial and Engineering Chemistry, 18, 513-519 (2012). DOI: $10.1016 /$ j.jiec. 2011.11.070

[12] Su P. G., Huang L. N.: Humidity sensors based on $\mathrm{TiO}_{2}$ nanoparticles/polypyrrole composite thin films. Sensors and Actuators B: Chemical, 123, 501-507 (2007). DOI: $10.1016 /$ j.snb.2006.09.052

[13] Cheng Q., He Y., Pavlinek V., Li C., Saha P.: Surfactant-assisted polypyrrole/titanate composite nanofibers: Morphology, structure and electrical properties. Synthetic Metals, 158, 953-957 (2008).

DOI: $10.1016 /$ j.synthmet.2008.06.022

[14] Alumaa A., Hallik A., Sammelselg V., Tamm J.: On the improvement of stability of polypyrrole films in aqueous solutions. Synthetic Metals, 157, 485-491 (2007). DOI: 10.1016/j.synthmet.2007.05.006

[15] Shaheen S. E., Brabec C. J., Sariciftci N. S., Padinger F., Fromherz T. Hummelen J. C.: 2.5\% efficient organic plastic solar cells. Applied Physics Letters, 78, 841843 (2001).

DOI: $10.1063 / 1.1345834$

[16] Deng F., Li Y., Luo X., Yang L., Tu X.: Preparation of conductive polypyrrole/ $/ \mathrm{TiO}_{2}$ nanocomposite via surface molecular imprinting technique and its photocatalytic activity under simulated solar light irradiation. Colloids and Surfaces A: Physicochemical and Engineering Aspects, 395, 183-189 (2012).

DOI: $10.1016 /$ j.colsurfa.2011.12.029

[17] Li J., Zhang Q., Feng J., Yan W.: Synthesis of PPymodified $\mathrm{TiO}_{2}$ composite in $\mathrm{H}_{2} \mathrm{SO}_{4}$ solution and its novel adsorption characteristics for organic dyes. Chemical Engineering Journal, 225, 766-775 (2013). DOI: $10.1016 /$ j.cej.2013.03.011 
[18] Jia Y., Xiao P., He H., Yao J., Liu F., Wang Z., Li Y.: Photoelectrochemical properties of polypyrrole $/ \mathrm{TiO}_{2}$ nanotube arrays nanocomposite under visible light. Applied Surface Science, 258, 6627-6631 (2012). DOI: 10.1016/j.apsusc.2012.03.092

[19] Zhu B., Zhu M., Zhang Q., Cheng L., Li Y., Wang H.: Conducting behaviors of PPy/ITO composites synthesized by polymerization. Synthetic Metals, 160, 21512154 (2010).

DOI: $10.1016 /$ j.synthmet.2010.07.045

[20] Zhang C., Li Q., Li J.: Synthesis and characterization of polypyrrole $/ \mathrm{TiO}_{2}$ composite by in situ polymerization method. Synthetic Metals, 160, 1699-1703 (2010). DOI: 10.1016/j.synthmet.2010.06.003

[21] Babazadeh M., Gohari F. R., Olad A.: Characterization and physical properties investigation of conducting polypyrrole/ $/ \mathrm{TiO}_{2}$ nanocomposites prepared through a one-step 'in situ' polymerization method. Journal of Applied Polymer Science, 123, 1922-1927 (2012). DOI: 10.1002/app.34689

[22] Zhang G., Choi W., Kim S. H., Hong S. B.: Selective photocatalytic degradation of aquatic pollutants by titania encapsulated into FAU-type zeolites. Journal of Hazardous Materials, 188, 198-205 (2011).

DOI: $10.1016 /$ j.jhazmat.2011.01.105

[23] Miyayama S., Nishijima K., Kamai T., Chiyoya T., Tsubota T., Ohno T.: Photocatalytic selective oxidation of anionic compounds on $\mathrm{TiO}_{2}$ photocatalysts modified with quaternary ammonium base groups. Separation and Purification Technology, 58, 206-210 (2007). DOI: $10.1016 /$ j.seppur.2007.07.030

[24] Inumaru K., Murashima M., Kasahara T., Yamanaka S.: Enhanced photocatalytic decomposition of 4-nonylphenol by surface-organografted $\mathrm{TiO}_{2}$ : A combination of molecular selective adsorption and photocatalysis. Applied Catalysis B: Environmental, 52, 275-280 (2004).

DOI: 10.1016/j.apcatb.2004.04.013

[25] Damin A., Llabrés i Xamena F. X., Lamberti C., Civalleri B., Zicovich-Wilson C. M., Zecchina A.: Structural, electronic, and vibrational properties of the Ti-O-Ti quantum wires in the titanosilicate ETS- 10 . The Journal of Physical Chemistry B, 108, 1328-1336 (2004). DOI: 10.1021/jp036902e

[26] Shen X., Zhu L., Li J., Tang H.: Synthesis of molecular imprinted polymer coated photocatalysts with high selectivity. Chemical Communications, 2007, 11631165 (2007).

DOI: $10.1039 / \mathrm{B} 615303 \mathrm{H}$
[27] Wang X-J., Xu Z-L., Feng J-L., Bing N-C., Yang ZG.: Molecularly imprinted membranes for the recognition of lovastatin acid in aqueous medium by a template analogue imprinting strategy. Journal of Membrane Science, 313, 97-105 (2008).

DOI: $10.1016 /$ j.memsci.2007.12.067

[28] Xiao D., Dramou P., Xiong N., He N., Li H., Yuan D., Dai H.: Development of novel molecularly imprinted magnetic solid-phase extraction materials based on magnetic carbon nanotubes and their application for the determination of gatifloxacin in serum samples coupled with high performance liquid chromatography. Journal of Chromatography A, 1274, 44-53 (2013).

DOI: $10.1016 /$ j.chroma.2012.12.011

[29] Duan Z., Yi J., Fang G., Fan L., Wang S.: A sensitive and selective imprinted solid phase extraction coupled to HPLC for simultaneous detection of trace quinoxaline-2-carboxylic acid and methyl-3-quinoxaline-2carboxylic acid in animal muscles. Food Chemistry, 139, 274-280 (2013).

DOI: 10.1016/j.foodchem.2013.02.007

[30] Shen X., Zhu L., Liu G., Yu H., Tang H.: Enhanced photocatalytic degradation and selective removal of nitrophenols by using surface molecular imprinted titania. Environmental Science and Technology, 42, 1687-1692 (2008). DOI: $10.1021 / \mathrm{es} 071788 \mathrm{p}$

[31] Zhao P., Hao J.: Tert-butylhydroquinone recognition of molecular imprinting electrochemical sensor based on core-shell nanoparticles. Food Chemistry, 139, 1001-1007 (2013).

DOI: $10.1016 /$ j.foodchem.2013.01.035

[32] Luo X., Deng F., Min L., Luo S., Guo B., Zeng G., Au C.: Facile one-step synthesis of inorganic-framework molecularly imprinted $\mathrm{TiO}_{2} / \mathrm{WO}_{3}$ nanocomposite and its molecular recognitive photocatalytic degradation of target contaminant. Environmental Science and Technology, 47, 7404-7412 (2013).

DOI: $10.1021 / \mathrm{es} 4013596$

[33] Huo P., Lu Z., Liu X., Wu D., Liu X., Pan J., Gao X., Guo W., Li H., Yan Y.: Preparation photocatalyst of selected photodegradation antibiotics by molecular imprinting technology onto $\mathrm{TiO}_{2} /$ fly-ash cenospheres. Chemical Engineering Journal, 189-190, 75-83 (2012).

DOI: $10.1016 /$ j.cej.2012.02.030

[34] Wang D., Wang Y., Li X., Luo Q., An J., Yue J.: Sunlight photocatalytic activity of polypyrrole- $-\mathrm{TiO}_{2}$ nanocomposites prepared by 'in situ' method. Catalysis Communication, 9, 1162-1166 (2008).

DOI: $10.1016 /$ j.catcom.2007.10.027 